\title{
Introduction: Why Reflect Collectively on Capacities for Change?'
}

\author{
Peter Clarke and Katy Oswald
}

\begin{abstract}
Capacity development' implies a promise of growing self-reliance, national ownership and sustainability, yet practice seems consistently to fall short of this emancipatory promise. This introduction argues for a reframing of capacity development for emancipatory social change. Articles in this IDS Bulletin show how understanding and practice must engage with complexity, appreciate the importance of specific culture and context, and continually address the role of power in shaping relationships, understandings and practices. Values and leadership are fundamental drivers of capacity development processes. This IDS Bulletin argues against a deficit approach based on linear causal logic and replicable 'best practice'. Instead, practitioners are encouraged to develop a detailed understanding of the culture and dynamics of specific contexts, to detect energies for positive change and work to connect and facilitate them. Learning is at the centre of the approach. Capacity development is understood as a collective process of learning in action for social change. Support for capacity development processes demands a critical development practice that implies mutual learning, with an emphasis on reflective and experiential approaches. However, this reframing implies enormous challenges for development practice, and therefore considerable personal and organisational commitment.
\end{abstract}

\begin{abstract}
'Neither researcher, administrator, nor villager is likely to achieve his or her potential for contribution to development until they join as partners in a mutual learning process, committed not to the search for magical blueprints, but to the building of new capacities for action.' (Korten 1980: 502)
\end{abstract}

\section{Reframing capacity for emancipatory social change}

Capacity development is a continuing subject of debate within development. It is a key term in the aid effectiveness discussions, most recently in the Accra Agenda (OECD/DAC 2008), and there are now multiple initiatives to learn more about it. ${ }^{2}$ The 'capacity development' concept implies a promise of gradually building self-reliance, national ownership and sustainability, yet practice seems to continually fall short of this emancipatory promise. As the editors of this IDS Bulletin, we argue that a commitment to this promise demands a significant shift in the way development is framed and practiced, and aim to contribute to the necessary reframing of capacity development for emancipatory social change.

We are building on a body of work by the Participation, Power and Social Change team at IDS which has looked at the way people living in poverty are largely cut off from avenues of power, and argues that the realisation of their rights depends on people and organisations having a better understanding of the dynamics of power with a view to changing them (Eyben et al. 2006). This implies that emancipatory social change, change that results in a shift in power relations in favour of marginalised or less powerful groups, should be a goal of development. It raises the question of what capacities are required to enable people and organisations to understand and change the dynamics of power. It also prompts us to ask if the causes of a lack of capacity, and of the difficulty of supporting capacity development, are often to be found in 
inequitable power relations (Morgan 1999). When framed in this way, support for capacity development becomes a political endeavour that engages with distinctive capacities and capacity development processes in distinctive ways, compared with a traditional approach to capacity development which is framed as a technical endeavour.

We argue that the debate about capacity development has largely been framed from a donor perspective, and call for an alternative approach that interrogates understandings and practices from other points of view, particularly the views of those seeking to develop their own capacity to contribute to processes of progressive social change. At the same time, this implies questioning the predominant framing of capacity development as a merely technical problem which is value-neutral.

If we are to interrogate capacity from the perspective of the active subjects of emancipatory processes, we need to be explicit about values, and focus on specific relationships, processes and culture in the messy complexity of particular contexts. A problem with traditional linear approaches to capacity development is that they view skills and knowledge as things to be transferred to fill a deficit, in specific individuals or organisations. We argue for a relational approach (Eyben 2008) which engages with complexity and sees capacity developing in and through relationships, as exemplified in work on multi-stakeholder processes (Woodhill 2004), and implies building on and with existing energies and capacities.

This IDS Bulletin reports on, and is part of, an ongoing collective inquiry into capacity, known as the Capacity Collective. This inquiry aims to connect experience from practice with theory, to make links with other bodies of practice and other disciplines, and to promote collective reflection on capacity development from a diversity of viewpoints.

In compiling this IDS Bulletin, we invited a diverse group of authors to contribute. Some would describe themselves as practitioners, others researchers, others policymakers and yet others as activists. We also strove to invite authors who might not normally be found in 'academic' publications. We found this challenging. It seemed that those who were engaged in 'doing' interesting and innovative things, were often the least able to find time to reflect and write about their experiences. Hence, we have achieved a relatively small number of contributions from Southern-based practitioners. This shortcoming has renewed our commitment to continue developing more effective ways of collaborating with diverse practitioners through the Capacity Collective.

This introductory article first outlines our understanding of capacity development, identifying three perspectives in the literature. It then goes on to argue for a reframing of capacity development for emancipatory social change, claiming that this can only be supported through a critical development practice that attends continuously to values and power. The rest of the article engages with three questions that we believe are essential to this critical development practice: what capacities are most needed to contribute to emancipatory social change; how do successful endogenous processes of capacity development take place; and how can processes of capacity development be supported purposefully?

\section{What is capacity development?}

Capacity development gradually emerged ${ }^{3}$ as a prominent theme in development policy in the late 1980 s and early $1990 \mathrm{~s}$, in response to criticism of the poor results of technical cooperation, and linked to increasing concern about both sustainability and state capacity. Skills transfer, through training and expatriate technical assistance, was failing to build sustainable impact, and instead dependency was being created (Morgan and Baser 1993: ii; Berg 1993: 244). The shift to capacity development implied a progressively more ambitious and comprehensive longer term engagement with the challenges of wider systemic factors, such as institutional incentives and organisational relations at national level (Morgan 1999: 16-18). Implicit in the capacity development agenda, then, was a promise of gradually building selfreliance, national ownership and sustainability through a long-term commitment.

Over the last decade, the development policy literature has continued to demonstrate convergence around the basic concepts. The definitions of the OECD/DAC have gained 
general acceptance. They define capacity as 'the ability of people, organisations and society as a whole to manage their affairs successfully', and capacity development as a 'process whereby people, organisations and society as a whole unleash, strengthen, create, adapt and maintain capacity over time' (OECD/DAC 2006: 12). Significantly, the DAC documents draw a clear distinction between capacity development as an endogenous process on the one hand, and outside support to this process, which is referred to as 'promotion of capacity development' (ibid.), on the other. In this respect, there is much less rigour in the broader literature, where what external agencies 'do' is often itself referred to as capacity development, with the risk of shifting the focus away from the endogenous process. This is indicative of a broader phenomenon, that while a great number of organisations express their agreement with the OECD definitions, in practice the literature displays a plethora of different applications of the term.

We have identified three specific perspectives in relation to the origin and value of the term, which we refer to as technical, discourse and emancipatory, each of which highlights quite different dimensions. Most literature draws on more than one of these perspectives. We adopt a critical stance towards each of these perspectives, but consider that each makes an important contribution to approaching capacity development, and that they should not be understood as mutually exclusive alternatives.

\subsection{A technical solution to a technical problem}

This is the predominant perspective in the policy literature, directed to answering the question: how can policy and practice contribute more effectively to development goals? The growing concern about aid effectiveness since the late 1990s has produced a vast and impressive policy literature on how capacity development should be supported, especially from the UNDP, the European Union and OECD. Most bilateral agencies have their own policy documents and guidance on practice. Other organisations have contributed substantially to a more critical conceptual and methodological discussion, including the European Centre for Development Policy Management (ECDPM), the Community Development Resource Association (CDRA), the International NGO Research and Training Centre (INTRAC) and Capacity.org.

\subsection{A discourse concealing an agenda of power?}

A number of authors distance themselves from the term 'capacity development', taking a perspective from outside development practice to analyse its self-serving use by development actors. Kühl (2009) argues that the adoption of the term is an attempt to legitimise in developed countries the activities of development organisations, and not a response to evidence from developing countries that capacity development actually works there. In his view northern organisations, faced with the difficulty of demonstrating the success of their development interventions, engage in a permanent pursuit of conceptual novelty, and:

the more these organisations are criticised... concerning their effectiveness, the more they must present new concepts to demonstrate their learning ability and to show that they will not give up the search for new and more effective strategies. (2009: 575)

Based on the work of Foucault on governmentality (1991), Philips and Ilcan (2004) suggest that capacity building can be viewed as a political technology of neoliberal governance, constructing compliant 'communities' to take responsibility for their own future, with consequences for the extent to which alternatives to dominant development paradigms may be imagined (2004: 405). However, they do not argue that this leads to a predestined future, and consider that the renegotiation of capacity building processes may 'hold seeds for growing other kinds of communities with other senses of responsibility' (ibid.).

\subsection{An aspiration for emancipatory development}

There is also a stream in the capacity development discussion where the term expresses an aspiration for social justice. From this perspective the development of capacity is an end in itself, closely related to goals of participation and empowerment. Morgan (1999: 18) refers to a perspective that has understood capacity building as 'a form of social mobilization with profound morale [sic], ethical, social and political overtones' with a concern for the causes of lack of capacity, which it roots in inequities and unequal power relationships. Black, for example, in a critical review of the capacity building literature, argues for more attention to 'the capacitation of the poor and marginalised to 
act as free and equal agents in determining the conditions of their lives' (2003: 118), and to 'the capacitation of donors, governments, and many development agencies to realign their own values, structures and agendas to counteract asymmetries of power that exacerbate systemic poverty and powerlessness' (ibid.). Similarly, Eade refers to a vision of Oxfam in which 'strengthening people's capacity to determine their own values and priorities and to act on these, is the basis of development' (1997: 2-3).

\subsection{The viewpoint of a critical development practice}

The predominant policy literature on capacity development defines it as a 'technical problem' and, by claiming neutrality, obscures the issues of values and power. Where support to capacity development takes this claim at face value, it will only reproduce unequal power relations. A focus on capacity development for emancipatory social change calls attention to the messy and political nature of capacity development and demands a critical development practice based on concerted and permanent attention to power and values.

From the point of view of an organisation or practitioner promoting capacity development for social change, each of the three perspectives identified above has a contribution to make, but the sequence is crucial. The emancipatory perspective affirms the importance of first clarifying personal and organisational values, as the driving force of practice. The discourse perspective is a reminder of structural limitations and power relations, and the role of practice in reproducing or renegotiating them. It challenges practitioners to question the coherence of their practice with their values and reflect on how power shapes perceptions, relations and outcomes. This permanent process of critical reflection on values and structural context is the necessary basis for the subsequent construction of methodology, for which the technical perspective offers support.

\subsection{Reframing capacity development for emancipatory social change}

The field of capacity development has largely been framed from a donor perspective. An approach to capacity development for emancipatory social change means interrogating understandings and practices from other perspectives. It values knowledge from specific change contexts, but especially from the viewpoints of active subjects of emancipatory struggles, and those seeking to develop their own capacities to contribute to processes of social change. These perspectives demand engagement with the specific relationships, processes and culture in the messy complexity of particular contexts. As recent work has argued (Eyben 2006; Ramalingam and Jones 2008), complexity has profound implications for the understanding and practice of development. Linear causal logic and replicable 'best practice' are inappropriate approaches to complex problems, and the kinds of systemic capacities needed to navigate complexity are unlikely to be built by straightforward transfers of skills to individuals or organisations.

We agree with Eyben (2008: 32) and Morgan that capacity development is about relations and about energy:

Networks of social relations form, center around certain values or ideas and unleash capacity in their participants. From this perspective capacity is as much about energy as it is about skills and resources. (Morgan 2005: 13)

In linear 'technical' approaches to capacity development, skills and knowledge are transferred to fill a deficit, in specific individuals or organisations. Such approaches imply a perspective from outside the change process. A relational approach (Eyben 2008), on the other hand, sees capacity developing in and through relationships, as exemplified in work on multistakeholder processes (Woodhill 2004). This also has implications for facilitators of capacity development processes, who need to see themselves as actors among others in social spaces where change takes place. They are part of the complex dynamic of change, and are themselves changed as they act to bring about change in the system. This implies openness to mutual learning (Pasteur and Scott-Villiers 2006). It also implies building on and with contextual energies and existing capacities.

\section{Collective inquiry to develop understanding and practice}

We aim to support the development of this reframing of capacity development for social change through collective inquiry rooted in contexts where capacities are developing. This IDS Bulletin reports on, but also forms part of 
this inquiry, in the framework of the 'Capacity Collective'. The strategy for this collective inquiry emerged out of a first workshop, convened by IDS in September 2007, where participants shared their concerns about the challenges and opportunities of support to capacity development (Taylor and Clarke 2008). A shared learning process was conceived, facilitating dialogue between researchers, practitioners, donors and technical agencies, but grounded in action research processes in specific contexts. IDS has therefore been working with funding from Irish Aid to support action research in contexts where social justice values are driving capacity development processes, to engage with understanding and promoting capacity development for change. The research involves varied groups, from universities and community organisations working together for change in Thailand, to a broad network of local organisations supporting child participation in a Nicaraguan town, and an organisation working to support African women in agricultural research. One of these initiatives is reported on in this IDS Bulletin in the article by Ortiz Aragón and Giles Macedo.

In each initiative we are promoting the surfacing and challenging of assumptions and the exploration of multiple perspectives, systemic issues and dimensions of power, while ensuring the capture and documentation of the learning process. Bringing diverse perspectives and ways of knowing into dialogue is a key strategy for shared learning within the Capacity Collective, and we are also facilitating shared reflection between initiatives and with a wider collective of actors and organisations.

\subsection{What do we need to know?}

The questions on which the Capacity Collective and this IDS Bulletin focus, arise specifically from a concern with capacity for social change.

Because capacities are not all equal, in the framework of a value-driven agenda, the first question is:

What capacities are most needed to contribute to emancipatory social change?

In order to respect the endogenous drivers of capacity development, it is important to understand better the dynamics of these processes. The second question is, therefore:
How do successful processes of capacity development take place?

And since we aspire to contribute to such processes, and there seems to be much to learn about effective practice in this field, the third question is:

How can processes of capacity development be supported purposefully?

\section{Responding to these questions}

The contributors to this IDS Bulletin represent a mix of: existing collaborators in the Capacity Collective who are currently engaged in actionresearch initiatives in that framework; other academics and practitioners who have long engaged in similar questions and whose work has contributed to the grounding of the Collective; and others who share interest and energy in exploring these questions.

\subsection{What capacities are most needed to contribute to emancipatory social change?}

Emancipatory social change involves challenging social norms, shifting power relations, and changing practices, but what capacities are needed to support these?

Capacities have been divided into 'hard' and 'soft', the former referring to, for example, the capacity to build infrastructure and manage finances; the latter referring to, for example, the capacity to manage knowledge or develop organisational procedures (Horton et al. 2003). 'Soft' capacities have also been divided into tangible and intangible (Kaplan 1999). Whereas the former are the visible systems and processes that may be in place, the latter refers to less obvious capacities such as the capacity to establish relationships. Whilst hard and soft, as well as tangible and intangible, capacities are all important, it is the soft and intangible capacities that are more difficult to identify and develop, but, as many of the articles in this IDS Bulletin show, are crucial in supporting emancipatory social change. This view is supported by Baser and Morgan (2008) in the ECDPM study on capacity, who found that in many cases, intangibles such as identity and confidence were of major significance in processes of capacity development.

\subsubsection{Navigating complexity}

We agree with Ortiz Aragón's argument in his article that social change is anything but straight 
forward, often trying to overcome ill-defined 'soft' problems which are complex and 'messy'. Woodhill's article makes a similar argument, stating that social systems are complex, due to multiple interacting institutions combined with the unpredictable nature of human behaviour. Both Ortiz Aragón and Woodhill agree that this complexity requires a different way of planning, implementing, monitoring and evaluating social change interventions, and therefore a need for the capacity to navigate such complexity. Both argue that organisations need to recognise and understand the implications of complex problems, including shifting from linear cause and effect models of how change happens, towards a more systemic understanding of how change happens. Both have different suggestions as to how this can be supported, which are discussed in 4.3 .

\subsubsection{Understanding and engaging with power}

Why do organisations need to understand and engage with power? In this IDS Bulletin, Woodhill argues that social change is not a neutral process. It involves challenging, and sometimes overcoming, existing authority and power. Therefore, organisations aiming to contribute to social change need to be able to engage politically, and develop the capacity to see and critically examine power relations, situating themselves within them. In Pettit's article he argues not just for the ability to understand power relations and situate oneself within them, but also to then strategise about how to engage with those power relations, either to challenge them or use them to one's advantage. Ortiz Aragón directly relates the need to understand power to the practice of capacity development. He analyses the concept of 'capacity' as a form of social capital, drawing on Bourdieu's theory of power (1977). He argues that if organisations can develop the ability to do this analysis themselves, it can help them understand why capacities are being developed - are they helping to transform or preserve existing power structures?

The issue of engagement with power highlights the critical relation of structure and agency. Our understanding (see section 2.4) of the way practice reproduces and renegotiates power relations, and of the need for critical development practice, implies a duality of structure and agency. This echoes theorists such as Bourdieu (1977) and Giddens (1984) who view structure as shaping human behaviour as well as itself being shaped by it.

In this IDS Bulletin, two articles engage directly with this duality when discussing the disconnect between the rhetoric and reality of capacity development. James, like other authors (Morgan 1999: 19; Black 2003: 17), considers that incentives in the aid system constrain attempts to improve practice in capacity development, for example, agencies have to follow donor rules; donors need to disburse quickly; and the competitive bidding system makes it difficult to identify, admit and address weaknesses. This might be seen to imply that some relatively modest adjustments of these procedures might resolve the difficulty. However, Harvey and Langdon take a more structural approach, describing how the emergence of empowering learning can be limited by the structures and incentives that govern the development system. They argue this is because the capacity to question not only the shape of development interventions, but the very contours through which those involved can imagine their identity, is curtailed.

However, they do not ignore the role of agency in addressing this problem. They call for a 'pedagogy of power' which prompts us to examine the forces that shape and constrain our own actions, to reflect upon the nature of our own power and agency, and to recognise one's capacity to shift power. For Harvey and Langdon, the capacity to shift power is required in order to achieve local self-determination and the imagining of an alternative identity, thus fulfilling the empowering promise of capacity development. James' approach also emphasises the agency of development organisations and practitioners but with a different solution that places responsibility on them to transform practice, by cultivating positive values. If we take James' proposal literally it may seem to exaggerate the agency of development practitioners and organisations, by putting the solution wholly in their hands. Yet, seen from the perspective of a development organisation or practitioner, it is important to take responsibility for one's own values and practice, rather than resort only to blaming structural constraints. One needs to have the courage to imagine and act differently. 


\subsubsection{Learning and adapting}

A further capacity identified by many of the articles in this IDS Bulletin is the capacity to learn and adapt. The organisational learning literature has, for many years, argued that the ability of an organisation to learn and adapt is fundamental to its functioning (Senge 2006; Flood 1999). Baser and Morgan (2008) identified the ability to adapt and self-renew as one of their five core capabilities that contribute to capacity. Similarly, in this IDS Bulletin, Pearson's article describes how a group of practitioners in Cambodia identified the need to practice effective approaches to learning as a means to contributing to social change. Woodhill's argument is that learning collaboratively supports innovation through the interaction of many different actors reflecting on a problem; therefore the ability to learn collaboratively is a significant contributor to social change. For Soal, the CDRA is such an innovative and creative organisation because of its capacity to learn and adapt, exemplified through its 'home weeks'.

\subsection{How do successful processes of capacity development take place?}

Capacity development is a process of endogenous change, but what are the dynamics and drivers of this endogenous process? How do capacities develop and why?

\subsubsection{Values and leadership}

Values and leadership are identified by articles in this IDS Bulletin as significant drivers of capacity development. Pitpit and Baser's article outlines a process of successful capacity development in Papua New Guinea, where the Office of the Public Solicitor has developed a social change vision based on clearly articulated values, and used this to build both its legitimacy and capacity more generally. Pitpit and Baser show how, for example, a vision that emphasises integrity and professionalism has encouraged staff to adopt better work practices, such as punctuality. Soal argues, based on her experience in the CDRA, that without purpose and without leadership, capacity does not develop.

\subsubsection{Relationships}

A notable dynamic that appears in several articles is relationships. Pitpit and Baser show how capacity within the Office of the Public Solicitor in Papua New Guinea has emerged out of fruitful relationships among people holding common ideals who want to make a difference, rather than just out of technical fixes. Reflecting on capacity development within a social movement, Margaret's article describes how learning is embedded, informal and unarticulated, mainly occurring through conversations and questioning between members of the social movement. She identifies dialogue and relationships as important means of facilitating capacity development.

Harvey and Langdon also emphasise the importance of relationships, but their focus is on how relationships can be both a facilitator and a hindrance to capacity development. They describe how troubled intergenerational relationships within a social movement in Ghana have led to a potential negation of emancipatory learning and a lessening of the capacity of the community to selfdetermination.

\subsubsection{Learning processes}

As well as the capacity to learn and adapt being significant in supporting social change, all the articles in this IDS Bulletin show how capacity development processes are themselves learning processes. Whatever the capacity, the processes through which it is developed will be a process of learning. This opens up a whole body of literature on learning. As Pettit argues in his article, the capacity development literature has had limited engagement with the traditions of adult education, critical pedagogy, and experiential learning. He points out that cognitive science is now increasingly shedding light on how creative and embodied methods, such as storytelling, drama and art, can support learning and that these approaches are now used for professional and leadership development in many sectors outside international development, yet are notably absent from traditional support to capacity development.

\subsection{How can processes of capacity development be supported purposefully?}

A number of articles in this IDS Bulletin explore concrete examples of methods and approaches that can inform purposeful practice to support capacity development.

\subsubsection{Working with existing energies}

Values-based practice cannot pretend to be neutral and is purposeful in seeking emancipatory change, but this does not imply imposing an external agenda. Several articles here imply that support for capacity development 
can only be successful when it works with energies for change that exist in the specific context. This implies the need to develop a detailed understanding of the culture and dynamics of the context, to find ways of detecting energies for positive change, and of working to connect and facilitate them. In her article, Pearson uses an apt analogy of the importance of pushing at (half) open doors. In the capacity development process she describes, she worked with a group of practitioners who she knew had an appetite and energy for learning, which she argues was a crucial driver of the process. There is little point in continuing to bang on closed doors. Pearson's approach emphasises a focus on identifying what drives organisations and using those drivers to support the development of capacity, rather than adopting a deficit approach which emphasises identifying capacity gaps in an organisation. Jackson also emphasises the importance of motivation and energy, warning that capacity is built through acts of learning, and unless people feel genuinely motivated to learn, participation in 'capacity development' processes will not lead to improved capacity.

\subsubsection{Critical reflection}

Pettit's article identifies the 'capacity challenge' of how to facilitate learning about the various forms of power in ways that go beyond gaining an analytical or conceptual grasp, and that can be put into practice. He identifies multiple dimensions of power (ranging from visible 'power over' to invisible internalised socialised norms) that he argues call for multiple dimensions of learning. For example, drawing on theory and practice from adult education, he argues that learning grounded in one's own experience which deepens critical reflection on one's own identity, values and position, leads to an understanding of one's own power. This emphasis on reflection and action as a means of supporting capacity development is also picked up by Margaret who describes the process of capacity development within a social movement as being best described as praxis. Praxis is a cycle of reflection and action that results in learning, although this learning is often only apparent when reflected upon.

However, Pettit highlights a gap within this literature on critical reflection. He argues that little is said about how we can reflect on and change internalised feelings of power, dispositions and emotions - the very reflexes that cause us to contradict our beliefs and widen the gaps between rhetoric and practice. This, Pettit argues, requires more creative methods, such as theatre, creative writing and storytelling, which are noticeably absent from the middle and higher echelons of aid organisations, and certainly from traditional capacity development interventions. This, Pettit argues, brings into question established methods of education and capacity development, particularly when aiming to develop the capacity to engage with and understand power.

\subsubsection{A systemic approach}

Several contributors consider that the capacity to navigate complexity also demands the adoption of a systemic approach. A 'systemic' approach attempts to understand the wider implications of the complex dynamics in which one is intervening, and attempts to support learning at multiple levels with multiple methods. Ortiz Aragón and Giles Macedo, in their article, describe an approach which they call systemic theories of change (STOG). This approach facilitates work in organisations to explore the question, 'What capacities are needed to effectively support positive change within this complexity?' In order to understand and navigate complexity, people and groups in organisations need to understand the many diverse perspectives on how social change happens; therefore, the approach works by facilitating collective critical reflection and discussion. However, adopting a systemic approach is challenging. In his article, Jackson reflects that the systemic approach he took to facilitating capacity development was unrealistic as the theory implies the ability to understand and influence all the factors affecting capacity, which is impossible to do. Therefore, he argues that our practice needs to be more aware of potential pitfalls of transferring systemic theory too literally or mechanically.

\subsubsection{Time and space for learning}

A particular challenge when supporting processes of capacity development is ensuring dedicated time, space and resources for learning. This is critical because, as argued above, the capacity to learn and adapt is important for supporting social change, but also because processes of capacity development are learning processes in themselves. 
Pearson's article reflects on a process supporting the development of the capacity to learn amongst practitioners in Cambodia. She rightly states that even the most dedicated practitioners convinced of the importance of learning find it difficult to make space for learning practices in the face of routine organisational busyness.

Participants in the process commented that this was something that they need but rarely get enough of. One described it as a 'delicious luxury'. If processes of learning are so valuable, how do we find the energies for learning? In an article reflecting on the practice of the CDRA, Soal argues that learning only happens with dedicated space. Responsibility for ensuring that learning happens cannot be delegated to people who do not have the authority to make it happen. However, as Soal points out, finding the time, space and commitment for learning is far from easy. It involves strong leadership, dedicated space and time, a specific rhythm and an approach which implies new ways of working and a strong sense of collegiality. This demands a radical shift in the ways organisations are structured and the incentives and priorities which the organisation sets and values. Learning needs to be valued as an activity in its own right.

\subsubsection{Acknowledging the challenges}

Ensuring that a learning process is demand-led is challenging. In this IDS Bulletin, Fisher warns that approaches that emphasise co-discovery, joint learning, critical reflection and adaptation explicitly demand far more effort on behalf of the learner and their organisation, and have less definite outcomes. She argues that for this kind of approach to be demand-led, all stakeholders must be committed to engaging in a process that is likely to be challenging, that will require change in all organisations and for which outcomes are uncertain. She concludes that it is unsurprising that most demands are for less problematic approaches to capacity development, such as training. Fisher quotes a participant from her own organisation who commented after a workshop to support capacity development: 'I learned as much from the other participants as they did from me, so was it really capacity development?' This quote shows the strength of preconceptions based on the one-sided knowledge transfer model of capacity development, despite the importance of mutual learning in supporting processes of capacity development.

\subsubsection{Working flexibly with methods}

A practice that is committed to engaging with the complexity of specific culture and context demands of the practitioner a flexible and creative attitude to methods. In her article, Pearson shows how both she and the learning group she facilitated were supported and guided by an approach she had experienced in another context. But this approach was not treated as a replicable blueprint. Its application in new contexts required a flexible and responsive engagement, based on thoughtful appreciation of contextual dynamics and culture.

\section{Conclusions and the way forward}

The articles in this IDS Bulletin contribute in many different ways to the reframing of capacity development for emancipatory social change. They show how understanding and practice must engage with complexity, appreciate the importance of specific culture and context, and address the role of power in shaping relationships, understandings and practices.

The authors identify the key importance of soft and intangible capacities to contribute to social change, and specifically explore the capacities to navigate complexity, to reflect critically, to engage with power and to learn and adapt. In seeking to understand how capacity develops endogenously, they show the critical role of values and leadership as drivers. By demonstrating that capacity development implies a collective learning process, they show the value of enriching understanding and practice by exploring literatures on critical and creative pedagogies. In addressing the challenge of how to support capacity development processes purposefully, an approach emerges that is very different from a deficit model based on linear causal logic and replicable 'best practice'. The kinds of systemic capacities needed to contribute to social change are unlikely to be built by straightforward transfers of skills to individuals or organisations. Instead practitioners are encouraged to develop a detailed understanding of the culture and dynamics of specific contexts, to detect energies for positive change and work to connect and facilitate them.

The critical development practice being proposed calls for methods and tools to be creatively adapted to the challenges of particular contexts. 
This implies a move from prescriptions to questions as the central form of methodological support. These questions should promote sustained critical reflection on practice, drawing on multiple perspectives, and using multiple methods, so that values and understandings become internalised and embodied. The aim should be to critically surface assumptions about change and the facilitator's role in it, and to understand the wider implications of the complex dynamics in which the intervention takes place. Such questions would include:

- What is the wider systemic context of the specific process or intervention that needs to be taken into account?

- What processes are already going on that can be learnt from, mobilised, supported?

- How does power play a role in the relationships and processes in the context?

- What different perspectives of key actors should play a role in shaping the change process?

- How do specific culture and context challenge the understanding of external actors?

Learning is at the centre of the approach presented here. On the one hand capacity development is understood as a collective process of learning in action for social change. On the other hand, support for capacity development

\section{Notes}

1 This article draws substantially on a process of shared inquiry and dialogue within the framework of the Capacity Collective, as well as on a body of work of members of the Participation, Power and Social Change Team at IDS. It draws more directly on joint research with Peter Taylor and Alfredo Ortiz Aragón, and previous working documents written with them. We are grateful for the financial support of Irish Aid which is making this work possible. We would also like to thank Alfredo Ortiz Aragón, Danny Burns, Jethro Pettit, John Gaventa, Paul Bennell, Peter Taylor and Rosalind Eyben for their helpful comments on earlier drafts of this article. processes demands a critical development practice that implies mutual learning, and an emphasis on reflective and experiential approaches. In addressing the question of why support for capacity development often fails to live up to its emancipatory promise, the articles suggest the huge scale of the challenge, and the commitment that is therefore demanded. The articles draw attention to the space and commitment that are necessary for learning to take place. Policy documents have long called for capacity development to be demand-led, and many writers have framed it as a mutual learning process. The articles here explore the enormous implications of these recommendations for ways of working. Mutual learning implies a fundamental shift from a model of knowledge transfer to one of creative co-discovery and co-creation of knowledge through collective critical reflection. It demands a fundamental renegotiation of power relations.

The questions and challenges addressed in this IDS Bulletin will continue to be explored in the framework of the Capacity Collective through action research as well as wider dialogues. This is not an exclusive or bounded group, and the collaborative nature of the inquiry is extended into a firm commitment to linking with the numerous other initiatives contributing to improved understanding and practices.

2 For example, the Learning Network on Capacity Development (LenCD), UNDP and Capacity.org.

3 In an influential 1999 study, Lusthaus et al. traced a gradual development in policy vocabulary from 'institution building' in the $50 \mathrm{~s}$ and $60 \mathrm{~s}$, to 'human resource development' in the $70 \mathrm{~s}$ and $80 \mathrm{~s}$, and then 'capacity building/development' in the late $80 \mathrm{~s}$ and $90 \mathrm{~s}$ (1999: 1-3). In 1993, Jaycox, then African Vice-President of the World Bank, claimed that the term was invented in a World Bank study (IBRD 1989), to 'distinguish a new mode of activity, a new way of doing business' (1993: 4). 


\section{References}

Baser, H. and Morgan, P. (2008) Capacity, Change and Performance: Study Report, Maastricht: European Centre for Development Policy Management (ECDPM)

Berg, E.J. (1993) Rethinking Technical Cooperation Reforms for Capacity Building in Africa, New York: United Nations Development Programme

Black, L. (2003) 'Critical Review of the CapacityBuilding Literature and Discourse', Development in Practice 13.1: 116-20

Bourdieu, P. (1977) Outline of a Theory of Practice, Cambridge: Cambridge University Press

Eade, D. (1997) Capacity Building: An Approach to People-centred Development, Oxford: Oxfam

Eyben, R. (2008) Power, Mutual Accountability and Responsibility in the Practice of International Aid: A Relational Approach, IDS Working Paper 305, Brighton: IDS

Eyben, R. (2006) 'Making Relationships Matter for Aid Bureaucracies', in R. Eyben (ed.), Relationships for Aid, London: Earthscan: 43-59

Eyben, R.; Harris C. and Pettit J. (2006) 'Introduction, Exploring Power for Change', IDS Bulletin 37.6, Brighton: IDS

Flood, R.L. (1999) Rethinking the Fifth Discipline: Learning within the Unknowable, London: Routledge

Foucault, M. (1991) 'Governmentality', in G. Burchell, C. Gordon and P. Miller (eds), The Foucault Effect: Studies in Governmentality, London: Harvester Wheatsheaf: 87-104

Giddens, A. (1984) The Constitution of Society: Outline of the Theory of Structuration, Cambridge: Polity

Horton, D.; Alexaki, A.; Bennett-Lartey, S.; Brice, K.N.; Campilan, D.; Carden, F.; de Souza Silva, J.; Duong, L.T.; Khadar, I.; Maestrey Boza, A.; Kayes Muniruzzaman, I.; Perez, J.; Somarriba Chang, M.; Vernooy, R. and Watts, J. (2003) Evaluating Capacity Development: Experiences from Research and Development Organizations Around the World, The Hague: International Service for National Agricultural Research (ISNAR)

International Bank for Reconstruction and Development (1989) Sub-Saharan Africa: From Crisis to Sustainable Growth: A Long-term Perspective Study, Washington DC: World Bank, www-wds.worldbank.org/external/default/ WDSContentServer/WDSP/IB/1999/12/02/ 000178830_98101901364149/Rendered/PDF/ multi0page.pdf (accessed 3 March 2010)
Jaycox, E.V.K. (1993) 'Capacity Building: The Missing Link in African Development', transcript of address to the African-American Institute Conference 'African Capacity Building: Effective and Enduring Partnerships', www.acdi-cida.gc.ca/inet/images.nsf/ vLUImages/CapacityDevelopment2/\$file/1993 \%20Jaycox\%20speech\%20on\%20CB\%20in\%20 Africa.pdf (accessed 3 March 2010)

Kaplan, A. (1999) The Developing of Capacity, Cape Town: Community Development Resource Association (CDRA)

Korten, D.C. (1980) 'Community Organization and Rural Development: A Learning Process Approach', Public Administration Review 40.5: $480-511$

Kühl, S. (2009) 'Capacity Development as the Model for Development Aid Organizations', Development and Change 40.3: 551-77

Lusthaus, C.; Adrien, M-H. and Perstinger, M. (1999) Capacity Development: Definitions, Issues and Implications for Planning, Monitoring and Evaluation, Montreal: Universalia

Morgan, P. (2005) The Idea and Practice of Systems Thinking and their Relevance for Capacity Development, Maastricht: European Centre for Development Policy Management (ECDPM) http://lencd.com/data/docs/118The \%20idea\%20and\%20practice \%20of\%20syst ems\%20thinking\%20and\%20their\%20rele.pdf (accessed 7 March 2010)

Morgan, P. (1999) 'Some Observations and Lessons on Capacity Building', in R. Maconick and P. Morgan (eds), Capacity Building Supported by the UN, New York: United Nations: 14-51

Morgan, P. and Baser, H. (1993) Making Technical Cooperation More Effective: New Approaches by the International Development Community, Gatineau: Canadian International Development Agency

OEGD/DAC (2008) The Paris Declaration on Aid Effectiveness and the Accra Agenda for Action, Paris: Organisation for Economic Cooperation and Development (OECD), www.oecd.org/dataoecd/1 1/41/34428351.pdf (accessed 10 March 2010)

OECD/DAC (2006) The Challenge of Capacity Development: Working towards Good Practice, Paris: Organisation for Economic Cooperation and Development (OECD)

Pasteur, K. and Scott-Villiers, P. (2006) 'Learning about Relationships in Development', in R. Eyben (ed.) Relationships for Aid, London: Earthscan: 94-112 
Philips, L. and Ilcan, S. (2004) 'CapacityBuilding: The Neo-liberal Governance of Development', Canadian Journal of Development Studies XXV.3: 393-409

Ramalingam, B. and Jones, H. (2008) Exploring the Science of Complexity: Ideas and Implications for Development and Humanitarian Efforts, London: Overseas Development Institute

Senge, P.M. (2006) The Fifth Discipline: The Art and Practice of the Learning Organisation, London: Random House
Taylor, P. and Clarke, P. (2008) Capacity for a Change: From the Capacity Collective Workshop, Brighton: IDS

Woodhill, J. (2004) 'Facilitating Complex MultiStakeholder Processes: A Social Learning Perspective,' working document, http://library.enaca.org/mangrove/publications /Woodhill_Facilitating_MSP.pdf (accessed 14 February 2010) 